\title{
Clinical significance of B7-H4 expression in matched non-small cell lung cancer brain metastases and primary tumors
}

This article was published in the following Dove Press journal:

OncoTargets and Therapy

9 July 2013

Number of times this article has been viewed

\author{
Zhen-ye $\mathrm{Li}^{2}$ \\ Xiang-heng Zhang' \\ Yu Chen' \\ Jian-gui Guo' \\ Ke Sai' \\ Qun-ying Yang' \\ Zhong-ping Chen' \\ Yong-gao Mou'
}

'State Key Laboratory of Oncology in South China, Department of Neurosurgery, Sun Yat-sen University Cancer Center, Guangzhou, ${ }^{2}$ Beijing Neurosurgical Institute, Capital Medical University, Beijing, People's Republic of China
Correspondence: Yong-gao Mou Department of Neurosurgery, Sun Yat-sen University Cancer Center, No 65I, Dong Feng Road E, Guangzhou 510060 , People's Republic of China Tel +86208734 33I I

Email mouyg@sysucc.org.cn
Background: B7-H4, a member of the inhibitory B7 family, is shown to have a profound inhibitory effect on the proliferation, activation, cytokine secretion, and development of cytotoxicity of $\mathrm{T}$ cells and may be involved in immune evasion in cancer patients. Although B7-H4 expression has been detected in non-small cell lung cancer (NSCLC), there are no published reports on the expression of B7-H4 in brain metastases from NSCLC.

Methods: We examined the expression of B7-H4 by immunohistochemistry in 49 cases of brain metastatic NSCLC, 18 cases of matched primary NSCLC, and 20 cases of NSCLC patients who had neither brain metastases nor other distant metastases.

Results: B7-H4 was highly expressed in 20 (40.8\%) out of 49 brain metastases and two $(11.1 \%)$ out of 18 matched primary tumors. The expression of B7-H4 in brain metastases appeared to be significantly higher than their matched primary tumors $(P=0.016)$. We also found that patients with high B7-H4 expression in their primary NSCLC have a higher risk of developing brain metastases $(P=0.022)$. Univariate analyses showed that median overall survival was significantly shorter in patients with high B7-H4 expression in brain metastases $(P=0.002)$. Multivariate analyses showed that B7-H4 was a significant independent prognostic indicator $(P=0.003)$.

Conclusion: NSCLC patients with high B7-H4 expression may benefit from aggressive treatment and close surveillance. Furthermore, our study suggests that B7-H4 may play an important role in the metastatic process of NSCLC and is promising to be a new immune checkpoint molecule for future antitumoral immunotherapy.

Keywords: B7-H4, brain metastases, non-small cell lung cancer, immunotherapy

\section{Introduction}

Lung cancer is the most common cause of cancer death worldwide, with nearly 1.6 million new cases and 1.4 million deaths estimated to have occurred in $2008 .{ }^{1}$ It was expected to account for $26 \%$ of all female cancer deaths and $29 \%$ of all male cancer deaths in the USA in 2012. ${ }^{2}$ Non-small cell lung cancer (NSCLC) accounts for approximately $85 \%$ of all lung cancer cases. ${ }^{3}$ Brain metastasis occurs in approximately $30 \%-50 \%$ patients with advanced NSCLC. ${ }^{4,5}$ The risk of developing brain metastases for patients in the early stages of NSCLC is up to $10 \% .{ }^{6}$ Due to earlier detection and better therapy, the incidence of brain metastases continues to increase.

The prognosis of patients with brain metastases from NSCLC is extremely poor. Without treatment, the median survival is only 1 month. ${ }^{7}$ In recent years, although many studies have shown that multidisciplinary treatment, including whole brain radiation therapy (WBRT), surgery, stereotactic radiosurgery, and chemotherapy, could improve the survival of NSCLC patients with brain metastases, the median survival 
is no more than 1 year. $^{8-11}$ Therefore, brain metastases will continue to be a major concern in the management of NSCLC and should receive more attention. It is important to understand the molecular mechanisms of brain metastases and to recognize patients with NSCLC who are at greater risk of developing them. ${ }^{12,13}$

The B7 family members play critical roles in the control and fine tuning of antigen-specific immune responses. ${ }^{14}$ B7-H4, also known as B7 ${ }_{\mathrm{X}}$ or B7S1, is a recently discovered member of this family thought to participate in negative regulation of cell-mediated immunity with a profound effect on the inhibition of T cell responses. ${ }^{14-16}$ B7-H4 mRNA has been found to be widely expressed in human peripheral tissues, including placenta, liver, skeletal muscle, kidney, pancreas, prostate, testis, ovary, small intestine, and brain. ${ }^{14-16}$ However, B7-H4 protein expression on the surface of cells seems to be limited. ${ }^{14-16}$ Recent studies have found that B7-H4 is overexpressed in various human tumors, including melanoma, breast, non-small cell lung, ovary, kidney, prostate, esophagus, pancreas, and stomach cancer, and has been shown to be a prognostic marker in some cancers and associated with cancer progression. ${ }^{17-25}$ Furthermore, naïve T cells, B cells, monocytes, and dendritic cell (DC) do not express B7-H4, but B7-H4 expression can be induced in these immunocytes after stimulation by IL- 6 and IL-10. ${ }^{14-16}$

Although B7-H4 expression has been detected in NSCLC and high B7-H4 expression has more commonly been found in lymph node metastasis patients, ${ }^{19}$ there are no published reports on the expression of $\mathrm{B} 7-\mathrm{H} 4$ in brain metastases from NSCLC. In the present study, we explore the expression of B7-H4 in brain metastases from NSCLC and their paired primary tumors by immunohistochemistry and aim to understand the clinical significance and role of B7-H4 in brain metastases.

\section{Materials and methods}

\section{Patients and tissue specimens}

Forty-nine patients pathologically diagnosed with brain metastases from NSCLC between January 2000 and December 2010 at Sun Yat-sen University Cancer Center (SYSUCC) were analyzed. All patients received craniotomy for brain metastases resection. In addition, 18 matched corresponding primary NSCLC were collected. Clinical parameters included patient demography, tumor histology, and the number of brain metastases. Additionally, patients were classified by recursive partitioning analysis (RPA). ${ }^{26}$ Four criteria were applied to stratify patients: Karnofsky performance status (KPS), primary tumor status, age, and presence of extracranial metastases. Class I: patients with KPS $\geq 70,<65$ years of age with controlled primary and no extracranial metastases; Class III: KPS $<70$; Class II: all others. Furthermore, 20 NSCLC patients who were treated in the same period from January 2000 to December 2010 with neither brain metastases nor other distant metastases were enrolled as a control group. All tissues were fixed in $10 \%$ buffered formalin and embedded in paraffin. All archival hematoxylin and eosin (H\&E)-stained sections were reviewed by two pathologists. The present study was approved by the Ethics Committee of Sun Yat-sen University Cancer Center.

\section{Immunohistochemistry staining}

Immunohistochemistry staining was performed using the two-step EnVision ${ }^{\mathrm{TM}}$ method (Dako, Glostrup, Denmark). Paraffin-embedded tissues were cut into $5 \mu \mathrm{m}$ serial sections, then transferred onto adhesive slides, and dried at $65^{\circ} \mathrm{C}$ for 30 minutes. The sections were deparaffinized with xylene and rehydrated through graded alcohols. Endogenous peroxidase activity was blocked with $0.3 \%$ hydrogen peroxide solution for 30 minutes and antigen retrieval was done at $100^{\circ} \mathrm{C}$ for 30 minutes in a citrate buffer $(10 \mathrm{mmol} / \mathrm{L}$; $\mathrm{pH}$ 6.0). After washing three times with phosphate buffered saline (PBS) for 5 minutes each, sections were incubated with $10 \%$ normal goat serum to block the nonspecific binding. Then sections were incubated with the rabbit antihuman B7-H4 monoclonal antibody (1:400 dilution; clone number EP1165; abcam) at $4{ }^{\circ} \mathrm{C}$ overnight, followed by immunodetection using the DAKO EnVision detection system (K5007). The slides were counterstained with Mayer's hematoxylin, dehydrated in graded alcohol, and mounted with a neutral resin. Negative control was carried out by replacing the primary antibody with PBS. Human tonsil tissue was used as positive control samples.

\section{Evaluation of B7-H4 staining}

The sections were examined and scored by two pathologists without knowledge of the patient's clinical record. Five tumor fields at $400 \times$ magnification were randomly selected. Cytoplasm and/or tumor cell membrane staining were considered to indicate positive expression. A previous semiquantitative system ${ }^{25}$ was used to determine B7-H4 expression. The proportion of positive cells was scored as follows: $0(<5 \%)$; $1(6 \%-25 \%)$; $2(26 \%-50 \%)$; $3(51 \%-$ $75 \%) ; 4(>75 \%)$. Staining intensity was evaluated as follows: 0 (no staining); 1 (weak staining, light yellow); 2 (moderate staining, yellowish brown); 3 (strong staining, brown). 
Sum score was determined by multiplying the positive proportion score by intensity score: 0 (negative); $1-4$ (weakly positive); 5-8 (moderately positive); 9-12 (strongly positive). In this study, B7-H4 expression was considered as low expression when the score was $<9$, and high expression when the score was $\geq 9$.

\section{Statistical analysis}

Statistical analysis was performed with SPSS (v17.0; IBM Corporation, Armonk, NY, USA) software. The relationship between B7-H4 expression and clinicopathologic characteristic were compared by the chi-square test or 2-tailed Fisher's exact test. McNemar's test for paired data was used to compare the frequency of B7-H4 expression between brain metastases and matched primary tumors. Two independent samples $t$-test was used to analyze the significance of $\mathrm{B} 7-\mathrm{H} 4$ expression scores between the matched corresponding primary NSCLC group and the control group. Overall survival (OS) was calculated from the diagnosis of brain metastases until death or the date of the last follow-up. Survival data were analyzed by the Kaplan-Meier method and long-rank test. The Cox proportional hazard model analysis was performed to identify the independent prognostic factors of survival. $P<0.05$ was considered statistically significant.

\section{Results}

\section{Clinical characteristics of patients}

A total of 49 patients with brain metastases from NSCLC were enrolled in the study, including 37 males and 12 females. All patients were followed up until March 2012, at which point 40 patients were confirmed to be deceased. The median age at the time of craniotomy was 53 years (range: 29-76 years). Of these patients, $36(73.5 \%)$ had solitary brain metastasis and $13(26.5 \%)$ had two or more brain metastases. RPA classification of patients was as follows: stage I $(n=13)$; stage II $(n=29)$; stage III $(n=7)$. Forty $(81.6 \%)$ patients received metastasectomy followed by WBRT, while nine patients received metastasectomy alone. The most commonly used fractionation schedule for WBRT was 30 Gy in ten fractions. Patients' characteristics are summarized in Table 1.

\section{Expression of B7-H4 in brain metastases and primary tumors}

Immunohistochemistry analysis demonstrated that B7-H4 was highly expressed in $20(40.8 \%)$ out of 49 brain metastases and two (11.1\%) out of 18 matched primary tumors
Table I Characteristics of patients with BMs

\begin{tabular}{ll}
\hline Characteristic & Number (\%) \\
\hline Age (years) & \\
$\quad$ Median & 53 \\
Range & $29-76$ \\
Gender & \\
$\quad$ Male & $37(75.5)$ \\
Female & $12(24.5)$ \\
Histology & \\
Adenocarcinoma & $42(85.7)$ \\
Squamous cell carcinoma & $4(8.2)$ \\
Adenosquamous carcinoma & $2(4.1)$ \\
Large cell carcinoma & $1(2.0)$ \\
RPA & \\
I & $13(26.5)$ \\
II & $29(59.2)$ \\
III & $7(14.3)$ \\
Number of brain metastases & \\
I & $36(73.5)$ \\
P2 & $13(26.5)$ \\
Primary tumor & \\
Controlled & $36(73.5)$ \\
Uncontrolled & $13(26.5)$ \\
Treatment modality & \\
Craniotomy + WBRT & $4 I(83.7)$ \\
Craniotomy only & $8(16.3)$ \\
\hline Abbreviations: BMs, brain metastases; RPA, recursive partitioning analysis; WBRT, \\
whole-brain radiotherapy.
\end{tabular}

(Figure 1). In order to determine the clinical significance of $\mathrm{B} 7-\mathrm{H} 4$ in brain metastases, we compared the expression of B7-H4 with clinicopathological characteristics of the patients. No significant association was found between the expression of B7-H4 and the age, gender, histology, RPA, number of brain metastases, condition of primary tumor, or treatment modality (Table 2).

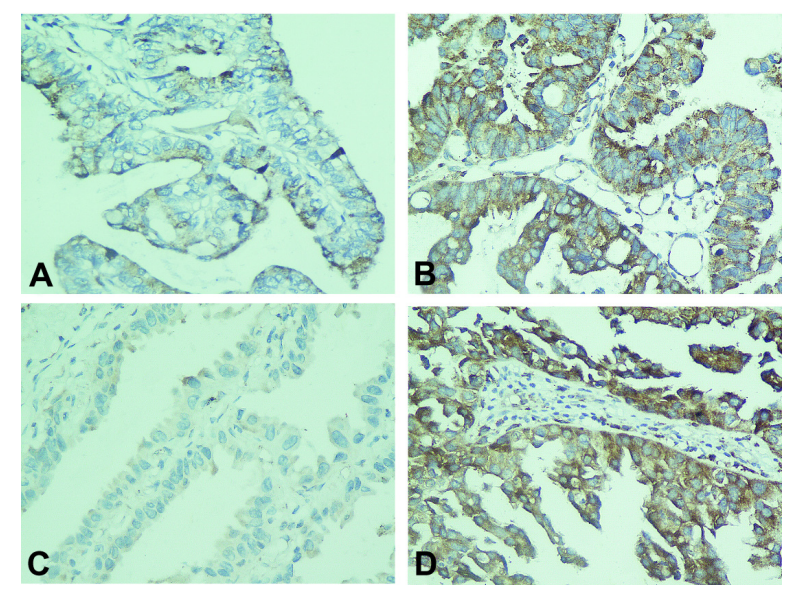

Figure I The B7-H4 expression in brain metastases from NSCLC (A) low expression; (B) high expression. Enhanced B7-H4 expression in brain metastases (D) as compared with the matched primary NSCLC (C).

Note: Magnification for all photomicrographs is $400 x$.

Abbreviation: NSCLC, non-small cell lung cancer. 
Table 2 Correlation between B7-H4 expression and clinical characteristics of patients with BMs

\begin{tabular}{|c|c|c|c|c|}
\hline \multirow[t]{2}{*}{ Characteristics } & \multirow[t]{2}{*}{ Number } & \multicolumn{2}{|l|}{ B7-H4 } & \multirow[t]{2}{*}{$P$-value } \\
\hline & & High (\%) & Low (\%) & \\
\hline Age (years) & & & & 0.737 \\
\hline$<55$ & 28 & $12(42.9)$ & $16(57.1)$ & \\
\hline$\geq 55$ & 21 & $8(38.1)$ & $13(61.9)$ & \\
\hline Gender & & & & 0.282 \\
\hline Male & 37 & I5 (40.5) & $22(59.5)$ & \\
\hline Female & 12 & $7(58.3)$ & $5(4 I .7)$ & \\
\hline Histology & & & & 1.000 \\
\hline Adenocarcinoma & 42 & $17(40.5)$ & $25(59.5)$ & \\
\hline Nonadenocarcinoma & 7 & $3(42.9)$ & $4(57.1)$ & \\
\hline RPA & & & & 0.195 \\
\hline 1 & 13 & $4(30.8)$ & $9(69.2)$ & \\
\hline II & 29 & II (37.9) & $18(62.1)$ & \\
\hline III & 7 & $5(7 \mid .4)$ & $2(28.6)$ & \\
\hline Number of BMs & & & & 0.076 \\
\hline I & 36 & $12(33.3)$ & $24(66.7)$ & \\
\hline$\geqslant 2$ & 13 & $8(6 \mid .5)$ & $5(38.5)$ & \\
\hline Primary tumor & & & & 0.265 \\
\hline Controlled & 36 & $13(36.1)$ & $23(63.9)$ & \\
\hline Uncontrolled & 13 & $7(53.8)$ & $6(46.2)$ & \\
\hline Treatment modality & & & & 0.700 \\
\hline Craniotomy + WBRT & 41 & $16(39.0)$ & $25(61.0)$ & \\
\hline Craniotomy only & 8 & $4(50.0)$ & $4(50.0)$ & \\
\hline
\end{tabular}

Abbreviations: BMs, brain metastases; RPA, recursive partitioning analysis; WBRT, whole brain radiation therapy.

\section{Differential expression of $\mathrm{B} 7-\mathrm{H} 4$ between paired tumors}

In seven cases, B7-H4 was highly expressed in the brain metastases but not as expressed in the matched primary tumors (Figure 1C and D). In addition, eleven cases had consistent B7-H4 expression status; in two cases, B7-H4 was highly expressed in the brain metastases and matched primary tumors, whereas nine cases showed low expression. The expression of B7-H4 in brain metastases appeared to be significantly higher than their matched primary tumors $(P=0.016)$.

\section{Differential expression of B7-H4 between the matched primary tumors group and the control group}

The expression of $\mathrm{B} 7-\mathrm{H} 4$ was evaluated according to the immunohistochemical score criterion as described in 'Materials and methods'. The scores of matched primary NSCLC were significantly higher than those of the NSCLC diagnosed during the same period of time $(P=0.022$; Figure 2$)$.

\section{Prognostic value of $\mathrm{B} 7-\mathrm{H} 4$ expression in brain metastases}

Kaplan-Meier analysis and the log-rank test were used to evaluate the effect of the B7-H4 expression on survival.

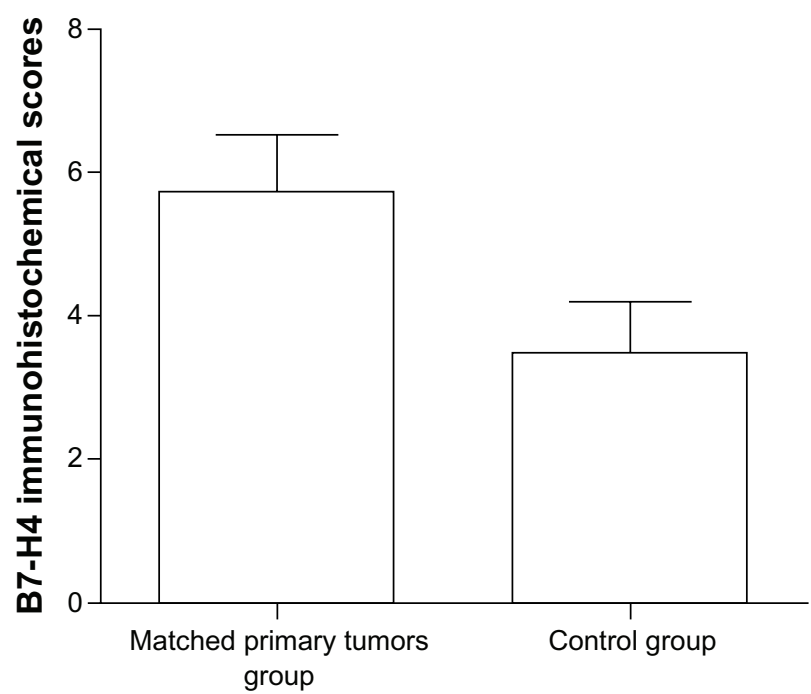

Figure 2 The matched primary tumors group had higher scores than the control group $(P=0.022)$

The median overall survival time was 14.6 months (95\% confidence interval [CI]: 8.2-21.0 months). In patients with high B7-H4 expression in brain metastases, the median survival time was 11.4 months (95\% CI: 5.8-16.9 months), compared with a median survival time of 26.2 months $(95 \%$ CI: 10.2-42.3 months) for patients with low B7-H4 expression $(P=0.002)$ (Figure 3$)$. The results of the univariate and multivariate survival analysis are shown in Tables 3 and 4. Low B7-H4 expression and metastasectomy followed by WBRT were positively correlated with survival by univariate analysis, and these were also independent prognostic factors in the multivariate analysis. In addition, low RPA and controlled primary tumors seemed to have positive effects on survival, but it was not significant in the multivariate analysis.

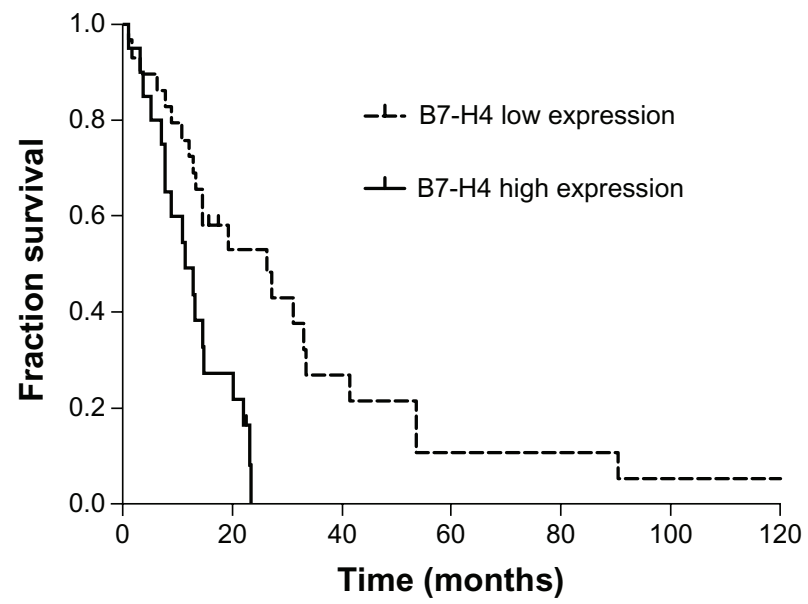

Figure 3 Patients whose brain metastases have high B7-H4 expression survived for a shorter time period than those with low expression according to Kaplan-Meier analysis $(P=0.002)$. 
Table 3 Univariate analysis of survival

\begin{tabular}{|c|c|c|c|c|}
\hline Variable & Cases & $\begin{array}{l}\text { Median } \\
\text { survival } \\
\text { (months) }\end{array}$ & $\begin{array}{l}95 \% \mathrm{Cl} \\
\text { (months) }\end{array}$ & $P$ value \\
\hline Age (years) & & & & 0.867 \\
\hline$<55$ & 28 & 14.7 & $5.0-24.4$ & \\
\hline$\geqslant 55$ & 21 & 14.5 & $12.0-17.0$ & \\
\hline Gender & & & & 0.182 \\
\hline Male & 37 & 19.2 & $10.5-28.0$ & \\
\hline Female & 12 & 12.1 & $8.2-16.0$ & \\
\hline Histology & & & & 0.244 \\
\hline Adenocarcinoma & 42 & 14.6 & $4.7-24.6$ & \\
\hline Nonadenocarcinoma & 7 & 13.2 & $12.3-14.2$ & \\
\hline RPA & & & & $<0.001$ \\
\hline I & 13 & 33.5 & $|5.9-5| . \mid$ & \\
\hline II & 29 & 14.5 & $12.5-16.5$ & \\
\hline III & 7 & 3.7 & $2.6-4.8$ & \\
\hline $\begin{array}{l}\text { Number of brain } \\
\text { metastases }\end{array}$ & & & & $0.08 I$ \\
\hline 1 & 36 & 20.1 & $10.3-30.0$ & \\
\hline$\geqslant 2$ & 13 & 12.1 & $7.1-17.2$ & \\
\hline Primary tumor & & & & $<0.001$ \\
\hline Controlled & 36 & 22.0 & $|2.2-3| .8$ & \\
\hline Uncontrolled & 13 & 9.3 & $4.0-9.9$ & \\
\hline Treatment modality & & & & $<0.001$ \\
\hline Craniotomy + WBRT & 41 & 20.1 & II.6-28.7 & \\
\hline Craniotomy only & 8 & 3.2 & $0.5-6.0$ & \\
\hline B7-H4 expression & & & & 0.002 \\
\hline Low & 29 & 26.2 & $10.2-42.3$ & \\
\hline High & 20 & 11.4 & $5.8-16.9$ & \\
\hline
\end{tabular}

Abbreviations: $\mathrm{Cl}$, confidence interval; RPA, recursive partitioning analysis; WBRT, whole-brain radiotherapy.

\section{Discussion}

Cancer cells can be recognized and attacked by $T$ cells of the immune system. Activation of T lymphocytes is initiated by antigen recognition. However, the balance of costimulatory and coinhibitory signals provided by the B7 family determines the final outcome of the immune response. Therefore, overexpression of inhibitory B7 family may lead to immunosuppression through the suppression of $\mathrm{T}$ cell function. Furthermore, the suppression of antitumor immune responses contributes to tumor evasion of immune surveillance.

Table 4 Multivariate analysis of survival

\begin{tabular}{llll}
\hline Variable & $\mathbf{R R}$ & $\mathbf{9 5 \%} \mathbf{C l}$ & $\boldsymbol{P}$-value \\
\hline Age & $\mathrm{I} .64$ & $0.77-3.5 \mathrm{I}$ & 0.199 \\
Gender & $\mathrm{I} .72$ & $0.70-4.19$ & 0.235 \\
Histology & 2.64 & $0.95-7.32$ & 0.062 \\
RPA & $2.0 \mathrm{I}$ & $0.9 \mathrm{I}-4.44$ & 0.084 \\
Number of brain metastases & $\mathrm{I} .20$ & $0.54-2.67$ & 0.650 \\
Primary tumor & 2.70 & $0.9 \mathrm{I}-8.03$ & 0.074 \\
Treatment modality & $\mathrm{I} .32$ & $3.53-66.5 \mathrm{I}$ & $<0.00 \mathrm{I}$ \\
B7-H4 expression & 3.46 & $\mathrm{I} .52-7.85$ & 0.003 \\
\hline
\end{tabular}

Abbreviations: $\mathrm{Cl}$, confidence interval; RPA, recursive partitioning analysis; $\mathrm{RR}$, relative risk.
B7-H4, a member of the inhibitory B7 family, is shown to have a profound inhibitory effect on the proliferation, activation, cytokine secretion, and development of cytotoxicity of $\mathrm{T}$ cells and may be involved in immune evasion in cancer patients. ${ }^{14-16}$ In this study, we reported that B7-H4 was expressed in human brain metastases from NSCLC and that there was a significant trend toward overexpression of B7-H4 in the brain metastases compared with the matched primary tumors. As far as we know, this is the first study to report the differential expression of B7-H4 between NSCLC brain metastases and their matched primary tumors. We also evaluated the expression of B7-H4 in patients with NSCLC with and without brain metastases in a series, demonstrating that the matched primary NSCLC group had higher immunohistochemical scores than the control group of NSCLC. Since survival in patients with brain metastases has been associated with several clinicopathological factors, we tried to define the relative contribution of $\mathrm{B} 7-\mathrm{H} 4$ expression to survival. Consistent with primary cancers, overexpression of B7-H4 in brain metastases indicates poor survival, suggesting that B7-H4 is an important prognostic factor for brain metastases patients.

Increased B7-H4 expression is involved in shaping the tumor microenvironment. A study ${ }^{27}$ found that $\mathrm{B} 7-\mathrm{H} 4$ is overexpressed in ovarian papillary serous adenocarcinoma, while mucinous and low malignant potential ovarian cancers and normal tissues were negative for B7-H4 . Another study ${ }^{28}$ demonstrated that the intensity of B7-H4 expression in macrophages was positively correlated with Treg cell numbers in ovarian tumors. Significant association was found between a high proportion of B7-H4 positive cells in NSCLC and a decreased number of tumor-infiltrating lymphocytes. ${ }^{19}$ In addition, B7-H4 was preferentially expressed in non-dividing tumor cells and in a subset of $\mathrm{CD} 133^{+}$stem cells. ${ }^{29}$

The function of B7-H4 in immune evasion in the cancer microenvironment is also to be elucidated. It has been found that B7-H4 inhibits $\mathrm{T}$ cell response by cell cycle arrest, with resultant inhibition of proliferation and cytokine secretion. ${ }^{14}$ Another study ${ }^{27}$ showed that increased B7-H4 expression on tumor cells correlated with both decreased apoptosis and enhanced growth of tumors. B7-H4 has also been shown to be variably glycosylated in tumor-specific patterns, suggesting glycosylation as a potential mechanism for modulating interaction of cytotoxic T cells (CTLs) with tumor cells. ${ }^{27}$ Recently, a study showed that B7-H4 inhibits T cell proliferation and interleukin-2 production by interfering with the activation of extracellular signal-regulated kinase (ERK), c-Jun N-terminal kinase (JNK), and protein kinase B (Akt). ${ }^{30}$ As such, the role of $\mathrm{B} 7-\mathrm{H} 4$ in tumor progression may 
be to transform precancerous cells and then to protect them from immunosurveillance. ${ }^{31}$

Consequently, recovering the capability of $\mathrm{T}$ cells to discover and attack cancer cells and promoting their anticancer response is a promising strategy in cancer therapy. Blocking the immune checkpoint molecule that would downregulate T cell immune response is one approach. In 2011, ipilimumab was approved as an inhibitory monoclonal antibody that blocks the immune checkpoint receptor cytotoxic T lymphocyte antigen 4 (CTLA-4) to promote antitumor immunity. It has been shown to improve survival in patients with metastatic melanoma. ${ }^{32}$ Recently, two early stage clinical trials ${ }^{33,34}$ reported that blocking the immune checkpoint molecule programmed death 1 (PD-1), a T cell coinhibitory receptor, and its ligand, PD-L1, can induce impressive durable responses in patients with advanced cancer. Silencing B7-H4 by small interfering RNA (siRNA) in activated hepatic stellate cells has been shown to restore the ability of T cells. ${ }^{35}$ siRNAmediated down-modulation of B7-H4 in a breast cancer cell line increased caspase activity, leading to apoptosis of tumor cells. ${ }^{27}$ Therefore, blocking the tumor-associated B7-H4 could represent a novel therapeutic approach to enhance antitumor immunity. However, the receptor of B7-H4 has not yet been discovered and identification of this receptor is crucial for complete understanding of B7-H4 function. As such, more studies are required.

Much evidence has shown differential expression of biomarkers in primary tumors and metastases. Our study also revealed discordances in B7-H4 expression between the primary NSCLC and the corresponding brain metastases. High expression of B7-H4 in the brain metastases may mean a further inhibitory effect on antitumor immune responses. Thus, B7-H4 is likely to play an important role in the process of brain metastasis.

Because of the poor prognosis of patients with brain metastasis from NSCLC, it is important to identify patients with NSCLC who are at greater risk of developing brain metastasis since they may exist in the absence of neurological symptoms. ${ }^{13}$ We found that patients with high B7-H4 expression in their primary NSCLC have a higher risk of developing brain metastasis. Therefore, high B7-H4 expression in NSCLC patients may indicate developing brain metastases, and calls for more aggressive treatment and close surveillance. Recently, soluble B7-H4 has also been detected in blood samples from cancer patients with higher B7-H4 levels correlated with advanced tumor stage. ${ }^{36}$ This result indicates that serum B7-H4 may be a potential diagnostic marker for brain metastases.
In summary, this study demonstrated that B7-H4 is overexpressed in brain metastases compared with the matched primary NSCLC. The overexpression of B7-H4 in brain metastases was correlated with poorer prognosis. In addition, NSCLC patients with high B7-H4 expression may benefit from aggressive treatment and close surveillance. Furthermore, our study suggests that B7-H4 may play an important role in the metastatic process of NSCLC and promises to be a new immune checkpoint molecule for future antitumoral immunotherapy.

\section{Acknowledgment}

This work was supported by the National Natural Science Foundation of China (30973080).

\section{Disclosure}

The authors report no conflicts of interest in this work.

\section{References}

1. Jemal A, Center MM, DeSantis C, Ward EM. Global patterns of cancer incidence and mortality rates and trends. Cancer Epidemiol Biomarkers Prev. 2010;19(8):1893-1907.

2. Siegel R, Naishadham D, Jemal A. Cancer statistics, 2012. CA Cancer J Clin. 2012;62(1):10-29.

3. Ramalingam SS, Owonikoko TK, Khuri FR. Lung cancer: new biological insights and recent therapeutic advances. CA Cancer J Clin. 2011;61(2):91-112.

4. Mamon HJ, Yeap BY, Janne PA, et al. High risk of brain metastases in surgically staged IIIA non-small-cell lung cancer patients treated with surgery, chemotherapy, and radiation. J Clin Oncol. 2005;23(7):1530-1537.

5. Wang SY, Ye X, Ou W, Lin YB, Zhang BB, Yang H. Risk of cerebral metastases for postoperative locally advanced non-small-cell lung cancer. Lung Cancer. 2009;64(2):238-243.

6. Hubbs JL, Boyd JA, Hollis D, Chino JP, Saynak M, Kelsey CR. Factors associated with the development of brain metastases: analysis of 975 patients with early stage nonsmall cell lung cancer. Cancer. 2010;116(21):5038-5046.

7. Lagerwaard FJ, Levendag PC, Nowak PJ, Eijkenboom WM, Hanssens PE, Schmitz PI. Identification of prognostic factors in patients with brain metastases: a review of 1292 patients. Int J Radiat Oncol Biol Phys. 1999;43(4):795-803

8. Patchell RA, Tibbs PA, Walsh JW, et al. A randomized trial of surgery in the treatment of single metastases to the brain. $N$ Engl $J$ Med. 1990;322(8):494-500.

9. Andrews DW, Scott CB, Sperduto PW, et al. Whole brain radiation therapy with or without stereotactic radiosurgery boost for patients with one to three brain metastases: phase III results of the RTOG 9508 randomised trial. Lancet. 2004;363(9422):1665-1672.

10. Hotta K, Kiura K, Ueoka H, et al. Effect of gefitinib ('Iressa', ZD1839) on brain metastases in patients with advanced non-small-cell lung cancer. Lung Cancer. 2004;46(2):255-261.

11. Lee DH, Han JY, Lee HG, et al. Gefitinib as a first-line therapy of advanced or metastatic adenocarcinoma of the lung in never-smokers. Clin Cancer Res. 2005;11(8):3032-3037.

12. Arnold SM, Young AB, Munn RK, Patchell RA, Nanayakkara N, Markesbery WR. Expression of p53, bcl-2, E-cadherin, matrix metalloproteinase-9, and tissue inhibitor of metalloproteinases-1 in paired primary tumors and brain metastasis. Clin Cancer Res. 1999;5(12): 4028-4033. 
13. Saad AG, Yeap BY, Thunnissen FB, et al. Immunohistochemical markers associated with brain metastases in patients with nonsmall cell lung carcinoma. Cancer. 2008;113(8):2129-2138.

14. Sica GL, Choi IH, Zhu G, et al. B7-H4, a molecule of the B7 family, negatively regulates T cell immunity. Immunity. 2003;18(6):849-861.

15. Zang X, Loke P, Kim J, Murphy K, Waitz R, Allison JP. B7x: a widely expressed B7 family member that inhibits T cell activation. Proc Natl Acad Sci U S A. 2003;100(18):10388-10392.

16. Prasad DV, Richards S, Mai XM, Dong C. B7S1, a novel B7 family member that negatively regulates $\mathrm{T}$ cell activation. Immunity. 2003;18(6):863-873.

17. Quandt D, Fiedler E, Boettcher D, Marsch WC, Seliger B. B7-H4 Expression in Human Melanoma: Its Association with Patients' Survival and Antitumor Immune Response. Clin Cancer Res. 2011;17(10): 3100-3111.

18. Tringler B, Zhuo S, Pilkington G, et al. B7-h4 is highly expressed in ductal and lobular breast cancer. Clin Cancer Res. 2005;11(5): 1842-1848.

19. Sun Y, Wang Y, Zhao J, et al. B7-H3 and B7-H4 expression in nonsmall-cell lung cancer. Lung Cancer. 2006;53(2):143-151.

20. Tringler B, Liu W, Corral L, et al. B7-H4 overexpression in ovarian tumors. Gynecol Oncol. 2006;100(1):44-52.

21. Krambeck AE, Thompson RH, Dong H, et al. B7-H4 expression in renal cell carcinoma and tumor vasculature: associations with cancer progression and survival. Proc Natl Acad Sci U S A. 2006;103(27): 10391-10396.

22. Zang X, Thompson RH, Al-Ahmadie HA, et al. B7-H3 and B7x are highly expressed in human prostate cancer and associated with disease spread and poor outcome. Proc Natl Acad Sci U S A. 2007;104(49):19458-19463.

23. Chen LJ, Sun J, Wu HY, et al. B7-H4 expression associates with cancer progression and predicts patient's survival in human esophageal squamous cell carcinoma. Cancer Immunol Immunother. 2011;60(7): 1047-1055.

24. Awadallah NS, Shroyer KR, Langer DA, et al. Detection of B7-H4 and p53 in pancreatic cancer: potential role as a cytological diagnostic adjunct. Pancreas. 2008;36(2):200-206.
25. Jiang J, Zhu Y, Wu C, et al. Tumor expression of B7-H4 predicts poor survival of patients suffering from gastric cancer. Cancer Immunol Immunother. 2010;59(11):1707-1714.

26. Gaspar L, Scott C, Rotman M, et al. Recursive partitioning analysis (RPA) of prognostic factors in three Radiation Therapy Oncology Group (RTOG) brain metastases trials. Int J Radiat Oncol Biol Phys. 1997;37(4):745-751.

27. Salceda S, Tang T, Kmet M, et al. The immunomodulatory protein B7-H4 is overexpressed in breast and ovarian cancers and promotes epithelial cell transformation. Exp Cell Res. 2005;306(1):128-141.

28. Kryczek I, Wei S, Zhu G, et al. Relationship between B7-H4, regulatory $\mathrm{T}$ cells, and patient outcome in human ovarian carcinoma. Cancer Res. 2007;67(18):8900-8905.

29. Yao Y, Wang X, Jin K, et al. B7-H4 is preferentially expressed in nondividing brain tumor cells and in a subset of brain tumor stem-like cells. J Neurooncol. 2008;89(2):121-129.

30. Wang X, Hao J, Metzger DL, et al. B7-H4 Treatment of T Cells Inhibits ERK, JNK, p38, and AKT Activation. PLoS One. 2012;7(1):e28232.

31. Yi KH, Chen L. Fine tuning the immune response through B7-H3 and B7-H4. Immunol Rev. 2009;229(1):145-151.

32. Hodi FS, O’Day SJ, McDermott DF, et al. Improved survival with ipilimumab in patients with metastatic melanoma. $N$ Engl $\mathrm{J} \mathrm{Med}$. 2010;363(8):711-723.

33. Topalian SL, Hodi FS, Brahmer JR, et al. Safety, activity, and immune correlates of anti-PD-1 antibody in cancer. NEngl J Med. 2012;366(26): 2443-2454.

34. Brahmer JR, Tykodi SS, Chow LQ, et al. Safety and activity of antiPD-L1 antibody in patients with advanced cancer. $N$ Engl J Med. 2012;366(26):2455-2465

35. Chinnadurai R, Grakoui A. B7-H4 mediates inhibition of T cell responses by activated murine hepatic stellate cells. Hepatology. 2010;52(6):2177-2185.

36. Thompson RH, Zang X, Lohse CM, et al. Serum-soluble B7X is elevated in renal cell carcinoma patients and is associated with advanced stage. Cancer Res. 2008;68(15):6054-6058.
OncoTargets and Therapy

\section{Publish your work in this journal}

OncoTargets and Therapy is an international, peer-reviewed, open access journal focusing on the pathological basis of all cancers, potential targets for therapy and treatment protocols employed to improve the management of cancer patients. The journal also focuses on the impact of management programs and new therapeutic agents and protocols on

\section{Dovepress}

patient perspectives such as quality of life, adherence and satisfaction The manuscript management system is completely online and includes a very quick and fair peer-review system, which is all easy to use. Visit http://www.dovepress.com/testimonials.php to read real quotes from published authors. 